Supplement of Biogeosciences Discuss., 12, 4107-4138, 2015

http://www.biogeosciences-discuss.net/12/4107/2015/

doi:10.5194/bgd-12-4107-2015-supplement

(C) Author(s) 2015. CC Attribution 3.0 License.

(c) (1)

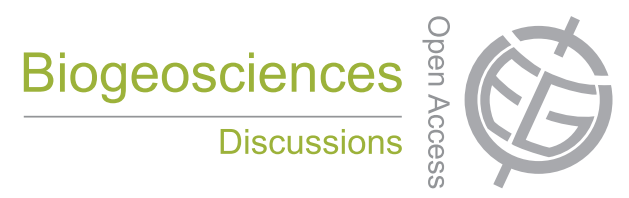

Supplement of

\title{
Seagrass meadows as a globally significant carbonate reservoir
}

I. Mazarrasa et al.

Correspondence to: I. Mazarrasa (imazarrasa@imedea.uib-csic.es) 
Supporting Information for

Seagrass meadows as a globally significant carbonate reservoir

Inés Mazarrasa, Núria Marbà, Catherine E. Lovelock, Oscar Serrano, Paul Lavery, James W. Fourqurean, Hilary Kennedy, Miguel A. Mateo, Dorte Krause-Jensen, Andrew D. L. Steven and Carlos M. Duarte

This document contains Table S1 and Figure S1. 
Table S1: Data descriptors of the observed, estimated and total data available on top meter PIC stocks (Mg PIC ha' ${ }^{-1}$ ).

\begin{tabular}{|l|c|c|c|c|c|c|}
\hline $\begin{array}{c}\text { Top meter stocks } \\
\left(\mathrm{Mg} \mathrm{PIC} \mathrm{ha}^{-1}\right)\end{array}$ & $\mathrm{N}$ & Mean & SE & Median & Max & Min \\
\hline Observed & 35 & 423.5 & 52.2 & 289.0 & 1189.5 & 17.9 \\
Estimated & 367 & 676.3 & 25.8 & 698.2 & 1660.0 & 3.1 \\
Total & 402 & 654.3 & 24.2 & 647.7 & 1660.0 & 3.1 \\
\hline
\end{tabular}


Figure S1: Carbon concentration $\left(\mathrm{mg} \mathrm{C} \mathrm{cm}^{-3}\right)$ (black and grey dots for POC and PIC respectively) along the top meter profile of the longest cores in the database ( $\mathrm{P} \geq 100$ $\mathrm{cm})$ that had a minimum of three different data reported over one meter depth $(\mathrm{n}=26)$. Meadow dominant genera and region are specified in each panel.

Carbon density $\left(\mathrm{mg} \mathrm{C} \mathrm{cm}{ }^{-3}\right)$
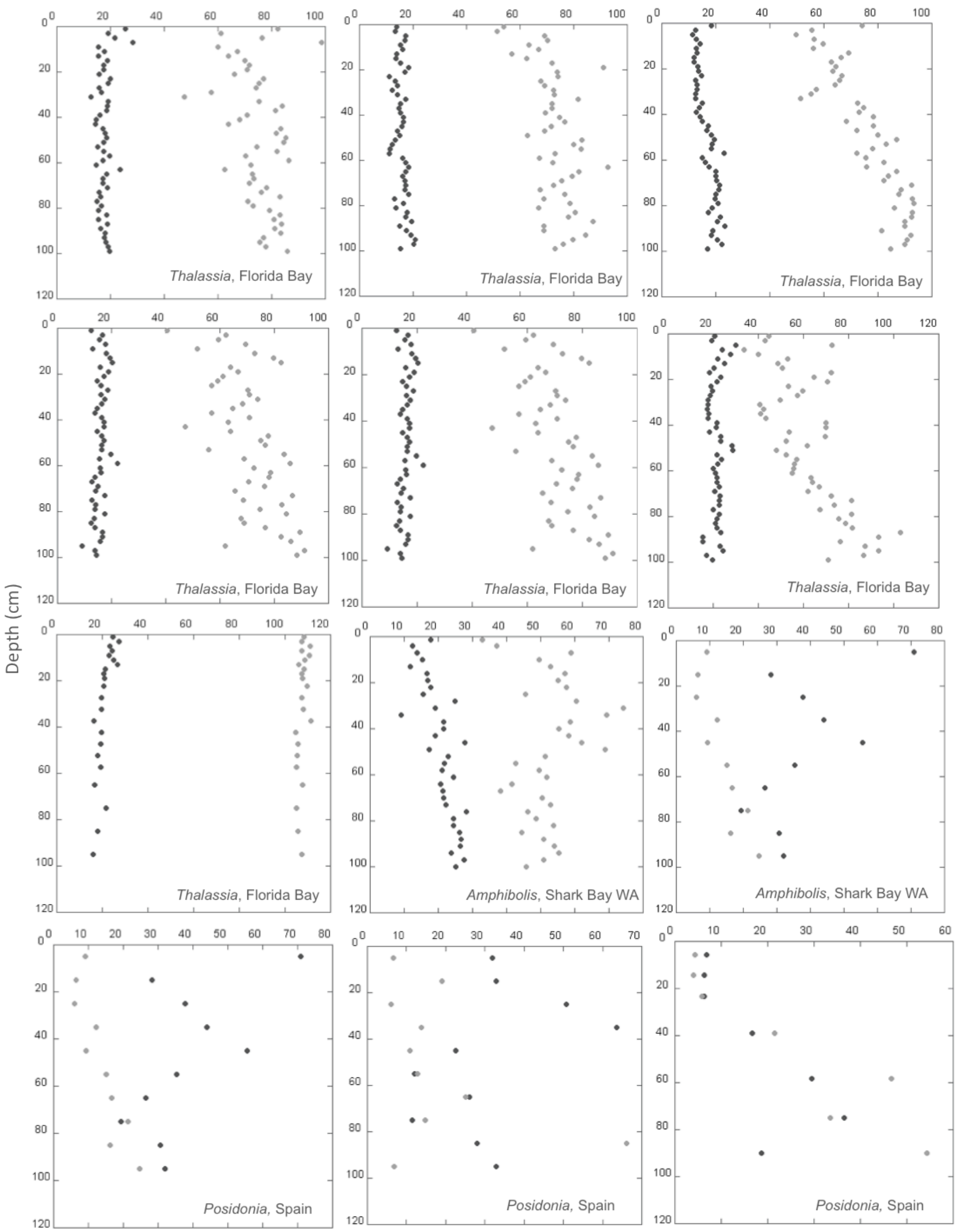

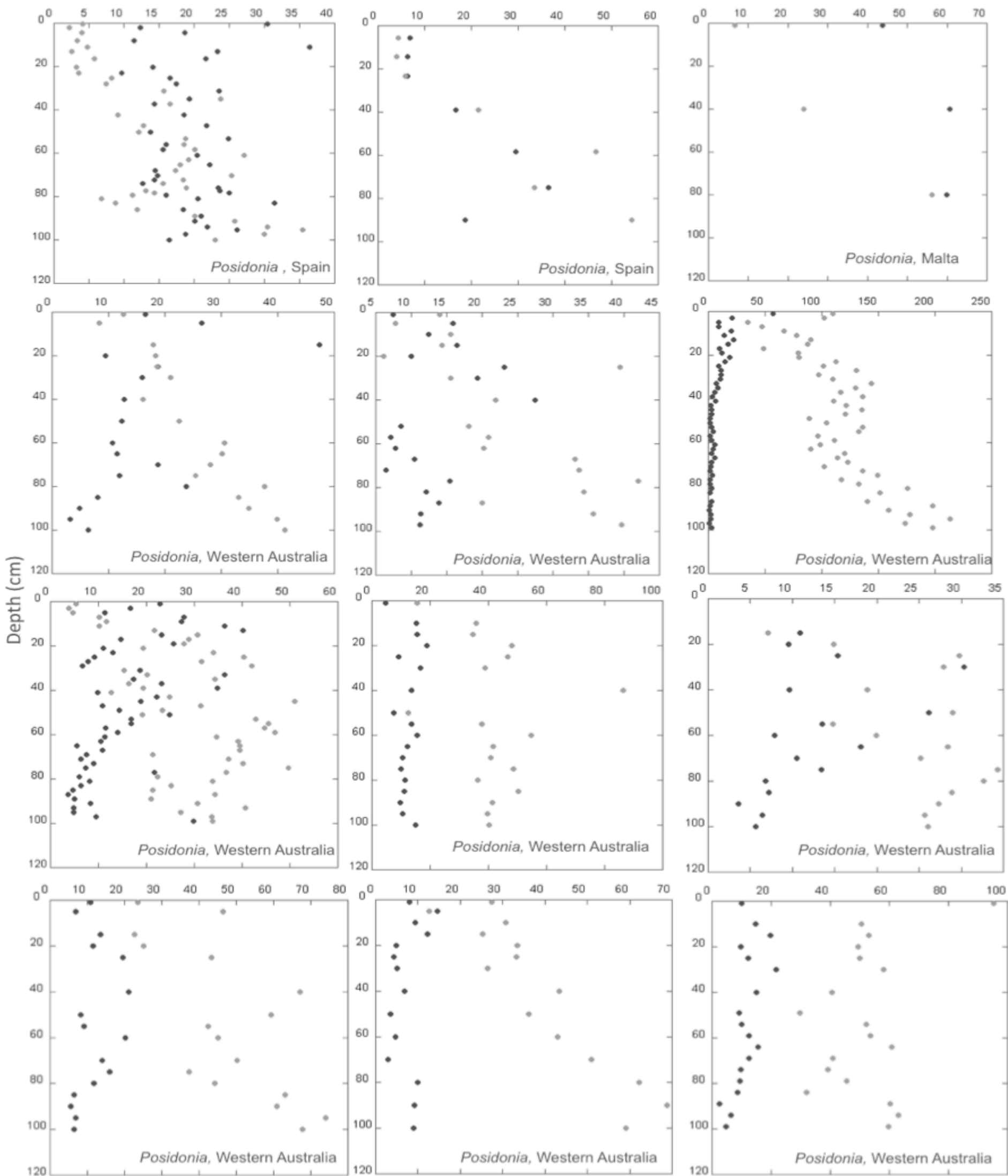

$\begin{array}{llllllll}0 & 10 & 20 & 30 & 40 & 50 & 60 & 70\end{array}$
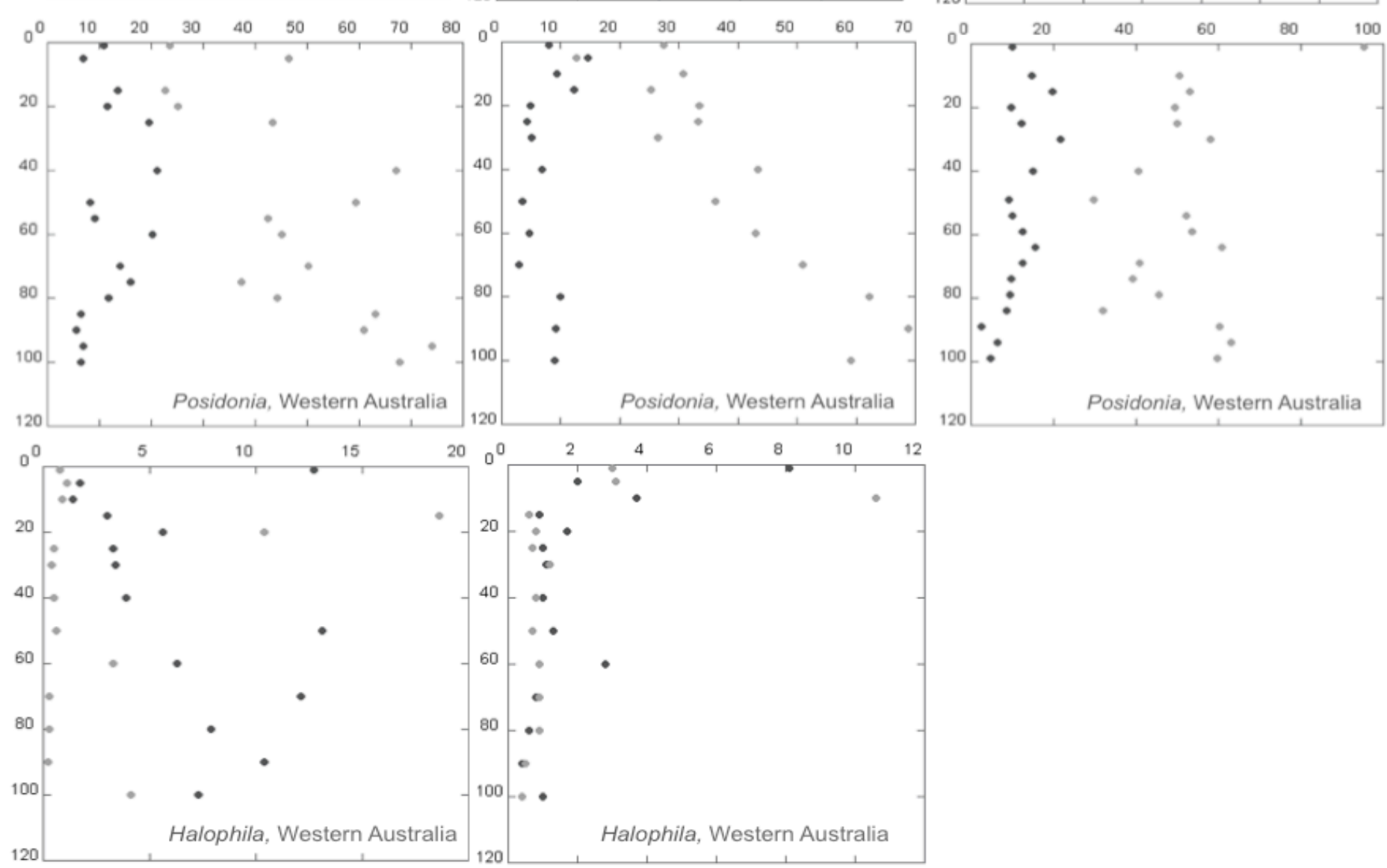
